\title{
CEACAM6 Gene Variants in Inflammatory Bowel Disease
}

\author{
Jürgen Glas ${ }^{1,2,39}$, Julia Seiderer ${ }^{19}$, Christoph Fries ${ }^{1,2}$, Cornelia Tillack ${ }^{1}$, Simone Pfennig ${ }^{1}$, Maria \\ Weidinger ${ }^{1}$, Florian Beigel ${ }^{1}$, Torsten Olszak ${ }^{1,4}$, Ulrich Lass ${ }^{5}$, Burkhard Göke ${ }^{1}$, Thomas Ochsenkühn ${ }^{1}$, \\ Christiane Wolf ${ }^{6}$, Peter Lohse ${ }^{7}$, Bertram Müller-Myhsok ${ }^{6}$, Julia Diegelmann ${ }^{1,2}$, Darina Czamara ${ }^{6}$, Stephan \\ Brand ${ }^{1 *}$
}

1 Department of Medicine II - Grosshadern, Ludwig-Maximilians-University, Munich, Germany, 2 Department of Preventive Dentistry and Periodontology, LudwigMaximilians-University, Munich, Germany, 3 Department of Human Genetics, Rheinisch-Westfälische Technische Hochschule, Aachen, Germany, 4 Division of Gastroenterology, Hepatology and Endoscopy, Brigham and Women's Hospital, Harvard Medical School, Boston, Massachusetts, United States of America, $\mathbf{5}$ TIB MOLBIOL Syntheselabor GmbH, Berlin, Germany, 6 Max-Planck-Institute of Psychiatry, Munich, Germany, 7 Department of Clinical Chemistry, Ludwig-MaximiliansUniversity, Munich, Germany

\begin{abstract}
Background: The carcinoembryonic antigen-related cell adhesion molecule 6 (CEACAM6) acts as a receptor for adherentinvasive E. coli (AIEC) and its ileal expression is increased in patients with Crohn's disease (CD). Given its contribution to the pathogenesis of $C D$, we aimed to investigate the role of genetic variants in the CEACAM6 region in patients with inflammatory bowel diseases (IBD).

Methodology: In this study, a total of 2,683 genomic DNA samples (including DNA from 858 CD patients, 475 patients with ulcerative colitis (UC), and 1,350 healthy, unrelated controls) was analyzed for eight CEACAM6 SNPs (rs10415946, rs1805223 = p.Pro42Pro, rs4803507, rs4803508, rs11548735=p.Gly239Val, rs7246116=pHis260His, rs2701, rs10416839). In addition, a detailed haplotype analysis and genotype-phenotype analysis were performed. Overall, our genotype analysis did not reveal any significant association of the investigated CEACAM6 SNPs and haplotypes with CD or UC susceptibility, although certain CEACAM6 SNPs modulated CEACAM6 expression in intestinal epithelial cell lines. Despite its function as receptor of AIEC in ileal CD, we found no association of the CEACAM6 SNPs with ileal or ileocolonic CD. Moreover, there was no evidence of epistasis between the analyzed CEACAM6 variants and the main CD-associated NOD2, IL23R and ATG16L1 variants.

Conclusions: This study represents the first detailed analysis of CEACAM6 variants in IBD patients. Despite its important role in bacterial attachment in ileal CD, we could not demonstrate a role for CEACAM6 variants in IBD susceptibility or regarding an ileal $C D$ phenotype. Further functional studies are required to analyze if these gene variants modulate ileal bacterial attachment.
\end{abstract}

Citation: Glas J, Seiderer J, Fries C, Tillack C, Pfennig S, et al. (2011) CEACAM6 Gene Variants in Inflammatory Bowel Disease. PLoS ONE 6(4): e19319. doi:10.1371/ journal.pone.0019319

Editor: Jörg Hermann Fritz, McGill University, Canada

Received May 6, 2010; Accepted March 31, 2011; Published April 29, 2011

Copyright: @ 2011 Glas et al. This is an open-access article distributed under the terms of the Creative Commons Attribution License, which permits unrestricted use, distribution, and reproduction in any medium, provided the original author and source are credited.

Funding: J. Glas was supported by a grant from the Broad Medical Foundation (IBD-0126R2). J. Seiderer and J. Diegelmann were supported by grants from the Ludwig-Maximilians-University Munich (FoeFoLe Nr. 422; Habilitationsstipendium, LMUExcellent to J.S. and Promotionsstipendium to J.D.); J. Seiderer was also supported by the Robert-Bosch-Foundation and the Else Kroener-Fresenius-Stiftung (81/08//EKMS08/01). S. Brand was supported by grants from the DFG (BR 1912/5-1), the Else Kroener-Fresenius-Stiftung (Else Kroener Fresenius Memorial Stipendium 2005; P50/05/EKMS05/62), by the Ludwig-Demling Grant 2007 from DCCV e.V., and by grants of Ludwig-Maximilians-University Munich (Excellence Initiative, Investment Funds 2008 and FFoLe program). U. Lass is a employee of TIB MOLBIOL Syntheselabor GmbH. The funders had no role in study design, data collection and analysis, decision to publish, or preparation of the manuscript. TIB MOLBIOL Syntheselabor GmbH provided help with designing the FRET probes but had no role in study design, data collection and analysis, decision to publish, or preparation of the manuscript.

Competing Interests: U. Lass is an employee of TIB MOLBIOL Syntheselabor GmbH, which is marketing FRET probes for genotyping. However, TIB MOLBIOL Syntheselabor $\mathrm{GmbH}$ had no role in study design, data collection and analysis, decision to publish, or preparation of the manuscript. The employment of U. Lass by TIB MOLBIOL Syntheselabor GmbH does not alter the authors' adherence to all the PLoS ONE policies on sharing data and materials.

*E-mail: stephan.brand@med.uni-muenchen.de

9 These authors contributed equally to this work.

\section{Introduction}

Crohn's disease $(\mathrm{CD})$ and ulcerative colitis $(\mathrm{UC})$ are chronic inflammatory bowel diseases (IBD), characterized by an aberrant mucosal immune response to bacteria-derived antigens in the gut of genetically susceptible hosts $[1,2]$. Although the exact pathogenesis of IBD still remains unsolved, current evidence indicates that defective T-cell apoptosis [3] and autophagy $[4,5,6,7]$ as well as an impairment of intestinal epithelial barrier function $[8,9]$ play important roles. This hypothesis is strengthened by data from genetic association studies identifying CD susceptibility genes involved in innate immunity and bacterial recognition (NOD2/CARD15) [10,11], and from genomewide association studies (GWAS), which identified susceptibility genes involved in autophagy (ATG16L1, IRGM) [4,5] and the proinflammatory IL-23/Th17 pathway [12].

While a specific causative pathogen in IBD has not been found so far $[13,14]$, investigations of the regulatory mechanisms operating at the mucosal level suggest that regulatory cells reactive to the 
commensal intestinal microflora might play a role in cross-reactive protection toward different bacterial antigens [15]. Moreover, there is raising evidence for a major role of certain bacteria such as adherent-invasive E. coli (AIEG) in ileal CD [16,17,18]. Interestingly, the carcinoembryonic antigen-related cell adhesion molecule 6 (CEACAM6) has recently shown to act as a receptor for AIEC, supporting ileal bacterial colonization as a major pathomechanism in CD [19]. The carcinoembryonic antigen (CEA) family consists of two subfamilies, the CEACAM subgroup and the pregnancy specific glycoprotein (PSG) subgroup [20,21]. CEACAM family members were found to be expressed in epithelial, endothelial, and hematopoietic cells, including T-lymphocytes, natural killer (NK) cells, dendritic cells (DC) and neutrophils. They may also be useful as biomarkers in cancer since they are often over-expressed in ovarian, endometrial, breast, lung, and colon carcinomas $[21,22,23]$. Depending on the tissue involved, CEACAMs are transmitting signals that result in a variety of effects including regulation of the cell cycle, tumor suppression, angiogenesis, lymphocyte activation and adhesion [22,23,24,25,26,27,28,29]. CEACAM1, CEACAM5, and CEACAM6 represent three of the CEACAM subfamily members expressed in intestinal epithelial cells. There is increased expression of CEACAM5 and CEACAM6 at the apical surface of the ileal epithelium in CD patients [19]. Moreover, ileal lesions in $\mathrm{CD}$ patients were found to be colonized by pathogenic AIEC [19], strengthening the hypothesis that an abnormal intestinal expression of CEACAM6 in CD patients is associated with an increased colonization of AIEC via type 1 pili expression inducing gut inflammation [18]. AIEC adhere to and invade intestinal epithelial cells [30] resulting in AIEC accumulation in macrophages leading to high amounts of TNF- $\alpha$ [31], thereby perpetuating intestinal inflammation.

Given the potential implication of dysfunctional CEACAM6 expression in the pathogenesis of IBD, we aimed to analyze the role of CEACAM6 SNPs in IBD susceptibility. A total of eight single nucleotide polymorphisms (SNPs) were analyzed in a large German cohort of CD and UC patients. Five SNPs in the CEACAM6 region (rs10415946, rs4803507, rs4803508, rs2701, rs10416839) were selected from the data of the international HapMap project covering the CEACAM6 gene plus $10 \mathrm{kB}$ flanking the centromeric and telomeric end of the gene, respectively. Additional selection criteria for the SNPs were a minor allele frequency of at least $5 \%$ and $a r^{2}$ of 1 . The SNPs rs4803507 and rs4803508 are localized in intron 2, rs2701 is localized within exon 6 encoding the $3^{\prime}$ untranslated region, while the SNPs rs 10415946 and rs 10416839 are within the $5^{\prime}$ - and the $3^{\prime}$-flanking region, respectively. Additionally, the coding variants rs $1805223=$ p.Pro42Pro (exon 2), $r$ s1 $1548735=$ p.Gly239Val and rs72461 16 $=$ pHis260His (exon 4) were investigated for which allele frequencies are published und which display a minor allele frequency of at least $5 \%$ in the Caucasian population. The structure of the CEACAM6 gene and the localization of the SNPs investigated in the presented study are shown in figure 1. Considering the abnormal expression of CEACAM6 in the ileal epithelium of CD patients and its role as receptor for ileal AIEC [19], we also analyzed for a potential association with an ileal CD phenotype and investigated potential gene-gene interactions with the NOD2 gene, which has been shown to be a strong predictor of ileal $\mathrm{CD}$, as well as with other $\mathrm{CD}$ susceptibility genes such as IL23R and ATG16L1.

\section{Materials and Methods}

\section{Ethics statement}

The study was approved by the local Ethics committee of the Ludwig-Maximilians-University of Munich (Department of Medicine) and adhered to the ethical principles for medical research involving human subjects of the Helsinki Declaration. Prior to the study, we obtained written, informed consent from all patients included.

\section{Study population and characterization of disease phenotype}

The study population comprised 858 patients with CD, 475 patients with UC, and 1350 healthy, unrelated controls of Caucasian origin. The study was approved by the local Ethics committee of the Ludwig-Maximilians-University of Munich (Department of Medicine) and adhered to the ethical principles for medical research involving human subjects of the Helsinki Declaration. Prior to the study, we obtained written, informed consent from all patients included. The phenotypic assessment was performed blind to the results of the genotypic data and included demographic data and clinical parameters (behaviour and anatomic location of IBD, disease-related complications, previous surgery or immunosuppressive therapy) which were recorded by investigation of patient charts and a detailed questionnaire. The diagnosis of $\mathrm{CD}$ or $\mathrm{UC}$ was based on established international guidelines including endoscopic, radiological, and histopathological criteria [32,33]. Patients with CD were assessed according to the Montreal classification [33] based on age at diagnosis (A), location (L), and behaviour (B) of disease. In patients with UC, anatomic location was also assessed in accordance to the Montreal classification [33], using the criteria ulcerative proctitis (E1), leftsided UC (distal UC; E2), and extensive UG (pancolitis; E3). Patients with indeterminate colitis were excluded from the study. The demographic and phenotypic data of the IBD study population are summarized in Table 1.

DNA extraction and genotyping of the CEACAM6 variants

Blood samples were taken from all participants of the study and genomic DNA was isolated from peripheral blood leukocytes using the DNA blood mini kit from Qiagen (Hilden, Germany)

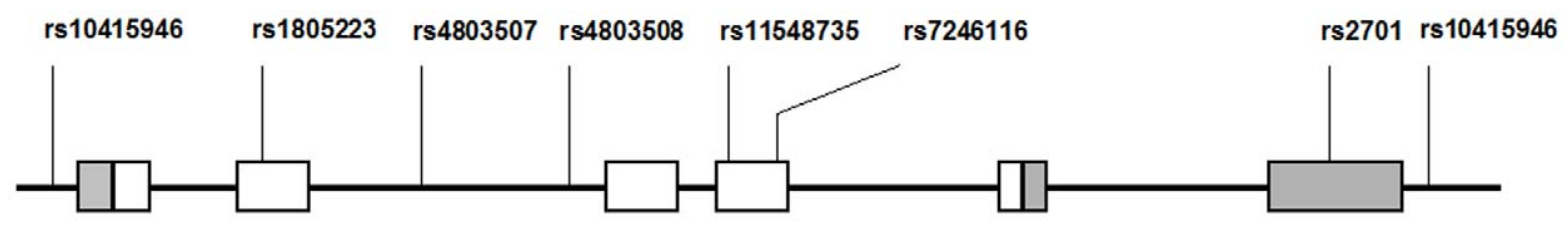

Figure 1. Exon-intron structure of the CEACAM6 gene and relative positions of single nucleotide polymorphisms (SNPs) investigated in the presented study. This figure represents the genomic structure of the CEACAM 6 gene consisting of 6 exons and indicates the positions of the CEACAM6 SNPs studied. The SNPs rs4803507 and rs4803508 are localized in intron 2, rs2701 is localized in exon 6 encoding the $3^{\prime}$-untranslated region, while the SNPs rs 10415946 and rs 10416839 are within the $5^{\prime}$ - and the $3^{\prime}$-flanking region, respectively. The coding variant rs $1805223=$ p.Pro42Pro is located in exon 2, while rs11548735 = p.Gly239Val and rs7246116=pHis260His are located in exon 4 . The grey part of exons 1 represents the $5^{\prime}$ untranslated region, the grey part of exons 5 and exon 6 represent the $3^{\prime}$ untranslated region.

doi:10.1371/journal.pone.0019319.g001 
Table 1. Demographic and phenotypic disease characteristics of the study population.

\begin{tabular}{|c|c|c|c|}
\hline & $\begin{array}{l}\text { Crohn's disease } \\
n=858\end{array}$ & $\begin{array}{l}\text { Ulcerative colitis } \\
n=475\end{array}$ & $\begin{array}{l}\text { Controls } \\
n=1350\end{array}$ \\
\hline \multicolumn{4}{|l|}{ Gender } \\
\hline Male (\%) & 45.3 & 47.9 & 62.6 \\
\hline Female (\%) & 54.7 & 52.5 & 37.4 \\
\hline \multicolumn{4}{|l|}{ Age (yrs) } \\
\hline Mean $\pm S D$ & $40.2 \pm 13.2$ & $42.4 \pm 14.4$ & $45.8 \pm 10.7$ \\
\hline Range & $11-81$ & $7-86$ & $18-71$ \\
\hline \multicolumn{4}{|l|}{ Body mass index } \\
\hline Mean \pm SD & $23.1 \pm 4.2$ & $23.9 \pm 4.1$ & \\
\hline Range & $13-40$ & $15-41$ & \\
\hline \multicolumn{4}{|l|}{ Age at diagnosis (yrs) } \\
\hline Mean $\pm \mathrm{SD}$ & $27.7 \pm 11.8$ & $32.0 \pm 13.3$ & \\
\hline Range & $1-78$ & $9-81$ & \\
\hline \multicolumn{4}{|l|}{ Disease duration (yrs) } \\
\hline Mean $\pm S D$ & $11.9 \pm 8.6$ & $10.5 \pm 7.7$ & \\
\hline Range & $0-44$ & $1-40$ & \\
\hline Positive family history of IBD (\%) & 16.0 & 16.1 & \\
\hline \multicolumn{4}{|l|}{ Disease localization (Crohn's disease) } \\
\hline \multicolumn{4}{|l|}{$n=764^{*}$} \\
\hline L1 (ileal) & 113 & & \\
\hline L2 (colonic) & 97 & & \\
\hline L3 (ileocolonic) & 554 & & \\
\hline + L4 (upper GI)** & 88 & & \\
\hline \multicolumn{4}{|l|}{ Disease behaviour (Crohn's disease) } \\
\hline \multicolumn{4}{|l|}{$n=754^{*}$} \\
\hline B1 (non-stricturing, non-penetrating) & 187 & & \\
\hline B2 (stricturing) & 208 & & \\
\hline B3 (penetrating) & 359 & & \\
\hline \multicolumn{4}{|l|}{ Disease extent (Ulcerative colitis) } \\
\hline \multicolumn{4}{|l|}{$n=260^{*}$} \\
\hline E1 (proctitis) & & 24 & \\
\hline E2 (left-sided UC) & & 96 & \\
\hline E3 (pancolitis) & & 140 & \\
\hline
\end{tabular}

according to the manufacturer's guidelines. Eight CEACAM6 SNPs (rs10415946, rs1805223=p.Pro42Pro, rs4803507, rs4803508, rs11548735 $=$ p.Gly239Val, $\quad$ rs7246116 $=$ pHis260His,$\quad$ rs2701, rs 10416839) were genotyped by PCR and melting curve analysis using a pair of fluorescence resonance energy transfer (FRET) probes in a LightCycler ${ }^{\circledR} 480$ Instrument (Roche Diagnostics, Mannheim, Germany) as described in previous studies [34,35,36]. The total volume of the PCR was $5 \mu$ l containing $25 \mathrm{ng}$ of genomic DNA, $1 \times$ Light Cycler 480 Genotyping Master Mix (Roche Diagnostics), 2.5 pmol of each primer and $0.75 \mathrm{pmol}$ of each FRET probe (TIB MOLBIOL, Berlin, Germany). In the case of rs 1805223, rs4803507 and rs4803508, the concentration of the forward primer, and in the case of rs10415946 and rs2701, the concentration of the reverse primer, were reduced to $1.25 \mathrm{pmol}$.
Two SNPs were analyzed in a multiplex reaction, the combinations were: rs10415946+rs4803508, rs1805223+rs4803507, rs $11548735+r s 7246116$ and rs2701+rs10416839. For the combination rs $11548735+$ rs 7246116 only one primer pair was used. The PCR comprised an initial denaturation step $\left(95^{\circ} \mathrm{C}\right.$ for $\left.10 \mathrm{~min}\right)$ and 45 cycles $\left(95^{\circ} \mathrm{C}\right.$ for $10^{\circ} \mathrm{C}$ sec, 60 for $10 \mathrm{sec}, 72^{\circ} \mathrm{C}$ for $\left.15 \mathrm{sec}\right)$. Details on the melting curve analysis and on the PCR used for sequencing were published in previous studies $[34,35,36]$. The PCR products were purified using the QIAquick PCR Purification Kit (Qiagen) and sequenced by a commercial sequencing company (Sequiserve, Vaterstetten, Germany). All sequences of primers and FRET probes and primer annealing temperatures used for genotyping and for sequence analysis are given in Tables 2 and 3 . 
Table 2. Primer sequences (F: forward primer, R: reverse Primer) and FRET probe sequences used for genotyping of CEACAM6 variants.

\begin{tabular}{|c|c|c|}
\hline Polymorphism & Primer sequences & FRET probe sequences \\
\hline rs10415946 & $\begin{array}{l}\text { F: AGCCCTGGATGTGTCCAC } \\
\text { A: AGTCCCTGGGTCCTCAA }\end{array}$ & $\begin{array}{l}\text { TGGATTACCCCCAGCAAG-FL } \\
\text { LC670-AGGTCACAGAGATGTITGGGGTCCTAG }\end{array}$ \\
\hline rs1805223 = p.Pro42Pro & $\begin{array}{l}\text { F: CCACCCTAATGCATAGGTCC } \\
\text { A: CGATTCTGTGGCAGGTTGT }\end{array}$ & $\begin{array}{l}\text { GAATCCACGCCATTCAATG-FL } \\
\text { LC670-CGCAGAGGGGAAGGAGGTTCTTC }\end{array}$ \\
\hline rs4803507 & $\begin{array}{l}\text { F: GCATCGTTCCTTCCTTTATGTA } \\
\text { A: TIITCCATAAGTGGAGATCGTT }\end{array}$ & $\begin{array}{l}\text { GAATTCACAACACACCTAAACC-FL } \\
\text { LC640-AGTATGTTATCAAGAAAAATACTACTTCCAGCCC }\end{array}$ \\
\hline rs4803508 & $\begin{array}{l}\text { F: CCTGTCCCCCTCACTGTCT } \\
\text { A: TITITCCATAAGTGGAGATCGTT }\end{array}$ & $\begin{array}{l}\text { CTGCTGAAAGATCCAATCCC-FL } \\
\text { LC610-GCCAGḠCTGCACAGTATCCTTGGG }\end{array}$ \\
\hline rs11548735 = p.Gly239Val & $\begin{array}{l}\text { F: TGGITGAGACTTCAGGGTTGT } \\
\text { A: TATGGGCTTGGCACATATAGG }\end{array}$ & $\begin{array}{l}\text { CCCAGATGTCCCCACCAT-FL } \\
\text { LC610-TCCC̄CCTCAAAGGCCAATTACCGTC }\end{array}$ \\
\hline rs7246116 = pHis260His & $\begin{array}{l}\text { F: TGGTTGAGACTTCAGGGTTGT } \\
\text { A: TATGGGCTTGGCACATATAGG }\end{array}$ & $\begin{array}{l}\text { CCTGCCACGCAGCCTCTA-FL } \\
\text { LC670-CCC̄ACCTGCACAGTACTCTTGGTTTATCAA }\end{array}$ \\
\hline rs2701 & $\begin{array}{l}\text { F: AAGATGTCAAAACAAGACTCCTCA } \\
\text { A: AAGTCCAACTCTGAAAAGGACC }\end{array}$ & $\begin{array}{l}\text { CAAGATAGATCTGACACTCTGTTAAGT-FL } \\
\text { LC610-ACCCTCTGAĀGCTACTTCTTGTGAAATACT }\end{array}$ \\
\hline rs10416839 & $\begin{array}{l}\text { F: CTTTCAGTTATATGTTGGCTCACTT } \\
\text { A: AAAAACACAGCATTATAGATCAACAG }\end{array}$ & $\begin{array}{l}\text { CCAGTGGCAGTTCCTCTG-FL } \\
\text { LC640-TGTAGT'CTGAATCAGGTGTACAACTGAGCC }\end{array}$ \\
\hline
\end{tabular}

Note: FL: Fluorescein, LC610: LightCycler-Red 610; LC640: LightCycler-Red 640. The polymorphic position within the sensor probe is underlined. A phosphate is linked to the 3 '-end of the acceptor probe to prevent elongation by the DNA polymerase in the PCR.

doi:10.1371/journal.pone.0019319.t002

Genotyping data of the three main CD-associated NOD2 variants p.Arg702Trp (rs2066844), p.Gly908Arg (rs2066845), and p.Leu1007fsX1008 (rs2066847) were available from previous studies [34,37]. Similarly, for epistasis analysis genotype data for the main CD-associated IL23R variants (rs1004819, rs7517847, rs10489629, rs2201841, rs11465804, rs1 1209026 (p.Arg381Gln), rs1343151, rs10889677, rs11209032, rs1495965) and ATG16L1 SNPs (rs13412102, rs12471449, rs6431660, rs1441090, rs2289472, rs2241880 (p.Thr300Ala), rs2241879, rs3792106, rs4663396) were available from previous studies [34-36].

\section{RNA isolation and quantitative PCR}

Total RNA was isolated from five intestinal epithelial cell (IEC) lines (DLD-1, HCT116, HT-29, SW480, T84) as indicated with the Qiagen RNeasy Kit and was reverse transcribed using Roche Transcriptor First Strand cDNA Synthesis Kit. Quantitative PCR was performed with SYBR Green PGR Master Mix from Roche on a LightCycler480 instrument. The following primers were used for amplification: CEACAM6 forward 5'-CACAACGTGCCCGAGAATCGTAT-3'; CEACAM6 reverse 5'-TTGGGCAGCTCGGGGTATACATG-3'; $\beta$-actin forward 5'-GCGAACGGCGAGAAGATGA-3'; $\beta$-actin reverse $5^{\prime}$-CATCACGATGCGAGTGGTA-3'. $\beta$-actin expression was used to normalize gene expression in the respective samples.

\section{Statistical analyses}

Each genetic marker was tested for Hardy-Weinberg equilibrium in the three subgroups of the study population. Fisher's exact test was used for comparison between categorical variables, while Student's t test was applied for quantitative variables. Singlemarker allelic tests were performed with Pearson's $\chi^{2}$ test. All tests were two-tailed, considering $\mathrm{p}$-values $<0.05$ as significant. Odds ratios were calculated for the minor allele at each SNP. For multiple comparisons, Bonferroni correction was applied where

Table 3. Primer sequences used for the sequence analysis of the CEACAM6 variants.

\begin{tabular}{|c|c|}
\hline Polymorphism & Primer sequences \\
\hline rs10415946 & $\begin{array}{l}\text { TGCAGAAAGAACAATTCAGAATCTTA } \\
\text { CTTGGGTCTGTCAGCACC }\end{array}$ \\
\hline rs1805223 = p.Pro42Pro & $\begin{array}{l}\text { GGGTGAAGAGACCTGCTCAG } \\
\text { CGCCTITGTACCAGCTGTAAC }\end{array}$ \\
\hline rs4803507 & $\begin{array}{l}\text { ACGTTGCTTCTAATTGGGCA } \\
\text { GAAAAGTTTGTCAGGAGTTTAGACC }\end{array}$ \\
\hline rs4803508 & $\begin{array}{l}\text { CCTGTCCCCCTCACTGTCT } \\
\text { ATGGGTGATGATGGGACTTC }\end{array}$ \\
\hline rs11548735 = p.Gly239Val, rs7246116 = pHis260His & $\begin{array}{l}\text { TGGITGAGACTTCAGGGTTGT } \\
\text { TATGGGCTGGCACATATAGG }\end{array}$ \\
\hline rs2701 & $\begin{array}{l}\text { AAGATGTCAAAACAAGACTCCTCA } \\
\text { AGAACAGGTGAGTCTAGAAGTCCA }\end{array}$ \\
\hline rs10416839 & $\begin{array}{l}\text { CTTCAGTTATATGTTGGCTCACTT } \\
\text { AAAAACACAGCATTATAGATCAACAG }\end{array}$ \\
\hline
\end{tabular}

doi:10.1371/journal.pone.0019319.t003 
Table 4. Associations of CEACAM6 gene markers in the case-control association studies.

\begin{tabular}{|c|c|c|c|c|c|c|c|c|c|}
\hline \multirow[t]{2}{*}{ SNP } & \multirow[t]{2}{*}{ Minor allele } & \multicolumn{3}{|c|}{$\begin{array}{l}\text { Crohn's disease } \\
n=858\end{array}$} & \multicolumn{3}{|c|}{$\begin{array}{l}\text { Ulcerative colitis } \\
n=475\end{array}$} & \multirow{2}{*}{$\begin{array}{l}\text { Controls } \\
n=1350 \\
\text { MAF/HWE }\end{array}$} & \multirow{2}{*}{$\begin{array}{l}\text { HapMap-CEU** } \\
n=120 \\
\text { MAF }\end{array}$} \\
\hline & & MAF/HWE & $p$ value & OR [95\% Cl] & MAF/HWE & $p$ value & OR $[95 \% \mathrm{Cl}]$ & & \\
\hline rs10415946 & G & $0.383 / 0.506$ & 0.21 & $1.08[0.96-1.23]$ & $0.338 / 0.113$ & 0.16 & $0.89[0.76-1.04]$ & $0.364 / 0.906$ & 0.440 \\
\hline rs1805223 = p.Pro42Pro & A & $0.309 / 0.679$ & 0.21 & $1.09[0.95-1.24]$ & $0.264 / 0.235$ & 0.12 & $0.87[0.74-1.03]$ & $0.291 / 0.262$ & 0.342 \\
\hline rs4803507 & A & $0.307 / 0.803$ & 0.24 & $1.08[0.96-1.24]$ & $0.269 / 0.454$ & 0.26 & $0.90[0.76-1.06]$ & $0.290 / 0.234$ & 0.280 \\
\hline rs4803508 & A & $0.377 / 0.266$ & 0.25 & $0.95[0.84-1.08]$ & $0.406 / 0.622$ & 0.35 & $1.07[0.92-1.25]$ & $0.389 / 0.606$ & 0.358 \\
\hline rs11548735 = p.Gly239Val & $\mathrm{T}$ & $0.399 / 0.885$ & 0.62 & $0.97[0.86-1.10]$ & $0.422 / 1$ & 0.44 & $1.06[0.92-1.24]$ & $0.407 / 0.612$ & 0.422 \\
\hline rs7246116 = pHis260His & T & $0 / *$ & 1.00 & - & $0.001 / 1$ & 0.26 & - & $0 / *$ & unknown \\
\hline rs2701 & G & $0.401 / 0.942$ & 0.62 & $0.97[0.85-1.09]$ & $0.423 / 0.903$ & 0.47 & $1.06[0.91-1.23]$ & $0.409 / 0.778$ & 0.408 \\
\hline rs10416839 & T & $0.359 / 0.653$ & 0.24 & $1.08[0.95-1.23]$ & $0.371 / 1$ & 0.11 & $1.14[0.97-1.32]$ & $0.341 / 0.545$ & 0.292 \\
\hline
\end{tabular}

Minor allele frequencies (MAF), $\mathrm{p}$-value for deviation from Hardy-Weinberg equilibrium (HWE), allelic test $P$-values, and odds ratios (OR, shown for the minor allele) with $95 \%$ confidence intervals $(\mathrm{Cl})$ are depicted for both the CD and UC case-control cohorts. Measurements for linkage disequilibrium (LD) are provided in Tables 11,12 and 13.

*monomorphic SNP.

**The MAFs in the HapMap-CEU population (= Utah residents with Northern and Western European ancestry) are derived from the NCBI SNP database (available under http://www.ncbi.nlm.nih.gov/snp).

doi:10.1371/journal.pone.0019319.t004

Table 5. Haplotypes of CEACAM6 SNPs in Crohn's disease (CD) case-control sample and omnibus p-values for association with CD susceptibility.

\begin{tabular}{|c|c|}
\hline Haplotype combination & omnibus p-value \\
\hline rs10415946-rs1805223 & 0.46 \\
\hline rs1805223-rs4803507 & 0.40 \\
\hline rs4803507-rs4803508 & 0.84 \\
\hline rs4803508-rs11548735 & 0.63 \\
\hline rs11548735-rs7246116 & 0.85 \\
\hline rs7246116-rs2701 & 0.78 \\
\hline rs2701-rs10416839 & 0.36 \\
\hline rs10415946-rs1805223-rs4803507 & 0.40 \\
\hline rs1805223-rs4803507-rs4803508 & 0.58 \\
\hline rs4803507-rs4803508-rs11548735 & 0.74 \\
\hline rs4803508-rs11548735-rs7246116 & 0.63 \\
\hline rs11548735-rs7246116-rs2701 & 0.74 \\
\hline rs7246116-rs2701-rs10416839 & 0.36 \\
\hline rs10415946-rs1805223-rs4803507-rs4803508 & 0.48 \\
\hline rs1805223-rs4803507-rs4803508-rs11548735 & 0.67 \\
\hline rs4803507-rs4803508-rs11548735-rs7246116 & 0.75 \\
\hline rs4803508-rs11548735-rs7246116-rs2701 & 0.39 \\
\hline rs11548735-rs7246116-rs2701-rs10416839 & 0.38 \\
\hline rs10415946-rs1805223-rs4803507-rs4803508-rs11548735 & 0.70 \\
\hline rs1805223-rs4803507-rs4803508-rs11548735-rs7246116 & 0.67 \\
\hline rs4803507-rs4803508-rs11548735-rs7246116-rs2701 & 0.59 \\
\hline rs4803508-rs11548735-rs7246116-rs2701-rs10416839 & 0.21 \\
\hline rs10415946-rs1805223-rs4803507-rs4803508-rs11548735-rs7246116 & 0.70 \\
\hline rs1805223-rs4803507-rs4803508-rs11548735-rs7246116-rs2701 & 0.66 \\
\hline rs4803507-rs4803508-rs11548735-rs7246116-rs2701-rs10416839 & 0.39 \\
\hline rs10415946-rs1805223-rs4803507-rs4803508-rs11548735-rs7246116-rs2701 & 0.77 \\
\hline rs1805223-rs4803507-rs4803508-rs11548735-rs7246116-rs2701-rs10416839 & 0.41 \\
\hline rs10415946-rs1805223-rs4803507-rs4803508-rs11548735-rs7246116-rs2701-rs10416839 & 0.39 \\
\hline
\end{tabular}

Given are the omnibus p-values for the CEACAM6 haplotype combinations regarding CD susceptibility.

doi:10.1371/journal.pone.0019319.t005 
Table 6. Haplotypes of CEACAM6 SNPs in ulcerative colitis (UC) case-control sample and omnibus p-values for association with UC susceptibility.

\begin{tabular}{|c|c|}
\hline Haplotype combination & omnibus p-value \\
\hline rs10415946-rs1805223 & 0.50 \\
\hline rs1805223-rs4803507 & 0.60 \\
\hline rs4803507-rs4803508 & 0.73 \\
\hline rs4803508-rs11548735 & 0.50 \\
\hline rs11548735-rs7246116 & 0.65 \\
\hline rs7246116-rs2701 & 0.55 \\
\hline rs2701-rs10416839 & 0.60 \\
\hline rs10415946-rs1805223-rs4803507 & 0.50 \\
\hline rs1805223-rs4803507-rs4803508 & 0.82 \\
\hline rs4803507-rs4803508-rs11548735 & 0.73 \\
\hline rs4803508-rs11548735-rs7246116 & 0.37 \\
\hline rs11548735-rs7246116-rs2701 & 0.69 \\
\hline rs7246116-rs2701-rs10416839 & 0.60 \\
\hline rs10415946-rs1805223-rs4803507-rs4803508 & 0.81 \\
\hline rs1805223-rs4803507-rs4803508-rs11548735 & 0.83 \\
\hline rs4803507-rs4803508-rs11548735-rs7246116 & 0.58 \\
\hline rs4803508-rs11548735-rs7246116-rs2701 & 0.50 \\
\hline rs11548735-rs7246116-rs2701-rs10416839 & 0.54 \\
\hline rs10415946-rs1805223-rs4803507-rs4803508-rs11548735 & 0.87 \\
\hline rs1805223-rs4803507-rs4803508-rs11548735-rs7246116 & 0.76 \\
\hline rs4803507-rs4803508-rs11548735-rs7246116-rs2701 & 0.55 \\
\hline rs4803508-rs11548735-rs7246116-rs2701-rs10416839 & 0.39 \\
\hline rs10415946-rs1805223-rs4803507-rs4803508-rs11548735-rs7246116 & 0.87 \\
\hline rs1805223-rs4803507-rs4803508-rs11548735-rs7246116-rs2701 & 0.75 \\
\hline rs4803507-rs4803508-rs11548735-rs7246116-rs2701-rs10416839 & 0.48 \\
\hline rs10415946-rs1805223-rs4803507-rs4803508-rs11548735-rs7246116-rs2701 & 0.87 \\
\hline rs1805223-rs4803507-rs4803508-rs11548735-rs7246116-rs2701-rs10416839 & 0.49 \\
\hline rs10415946-rs1805223-rs4803507-rs4803508-rs11548735-rs7246116-rs2701-rs10416839 & 0.82 \\
\hline
\end{tabular}

Given are the omnibus p-values for the CEACAM6 haplotype combinations regarding UC susceptibility.

doi:10.1371/journal.pone.0019319.t006

Table 7. Associations of CEACAM6 gene markers with the anatomic location of Crohn's disease (CD) according to the Montreal classification [33].

\begin{tabular}{|c|c|c|c|c|c|c|c|c|}
\hline $\begin{array}{l}\text { Anatomic } \\
\text { location }\end{array}$ & rs10415946 & $\begin{array}{l}\text { rs } 1805223= \\
\text { p.Pro42Pro }\end{array}$ & rs4803507 & rs4803508 & $\begin{array}{l}\text { rs11548735 = } \\
\text { p.Gly239Val }\end{array}$ & $\begin{array}{l}\text { rs7246116 = } \\
\text { pHis260His }\end{array}$ & rs2701 & rs10416839 \\
\hline $\begin{array}{l}\text { L1 (ileal) } \\
n=113\end{array}$ & 0.320 & 0.321 & 0.559 & 0.876 & 0.961 & $*$ & 0.997 & 0.566 \\
\hline $\begin{array}{l}\text { L2 (colonic) } \\
n=97\end{array}$ & 0.854 & 0.988 & 0.970 & 0.611 & 0.751 & $*$ & 0.684 & 0.580 \\
\hline $\begin{array}{l}\text { L3 (ileocolonic) } \\
n=554\end{array}$ & 0.451 & 0.759 & 0.803 & 0.425 & 0.684 & $*$ & 0.691 & 0.114 \\
\hline $\begin{array}{l}\text { Any ileal } \\
\text { involvement } \\
\text { (L1+L3) } \\
n=667\end{array}$ & 0.373 & 0.586 & 0.689 & 0.620 & 0.771 & $*$ & 0.744 & 0.117 \\
\hline
\end{tabular}

$P$-values are depicted for the CD case-control cohorts.

*There were no carriers of the minor allele of rs7146116 in the CD and control cohort.

doi:10.1371/journal.pone.0019319.t007 
Table 8. Analysis for gene-gene interactions between CEACAM6 and NOD2 variants regarding susceptibility to Crohn's disease (CD).

\begin{tabular}{|c|c|c|c|c|c|c|c|c|}
\hline $\begin{array}{l}\text { CEACAM6 } \\
\text { SNPs } \\
\text { NOD2 SNPs }\end{array}$ & rs10415946 & rs1805223 & rs4803507 & rs4803508 & rs11548735 & rs7246116 & rs2701 & rs10416839 \\
\hline rs2066844 p.Arg702Trp & 0.56 & 0.37 & 0.39 & 0.31 & 0.62 & * & 0.65 & 0.77 \\
\hline rs2066845 p.Gly908Arg & 0.06 & 0.28 & 0.28 & 0.54 & 0.35 & * & 0.43 & 0.58 \\
\hline rs2066847 p.Leu1007fsX1008 & 0.93 & 0.80 & 0.97 & 0.51 & 0.71 & * & 0.56 & 0.82 \\
\hline
\end{tabular}

p-values for epistasis analysis between CEACAM6 and NOD2 SNPs in the CD case-control sample.

*There were no carriers of the minor allele of rs7146116 in the CD and control cohort.

doi:10.1371/journal.pone.0019319.t008

indicated. Interactions between different polymorphisms were tested using logistic regression in $\mathrm{R}$ using the number of minor alleles as predictor variable, therefore implementing an Armitage test of trend. Data were evaluated by using the SPSS 13.0 software (SPSS Inc., Chicago, IL, USA) and R-2.4.1. (http://cran.r-project. org). For haplotype analysis, PLINK v 1.06 (http://pngu.mgh. harvard.edu/ purcell/plink/) was used running a sliding window approach with variation of the window size from 2 to 8 included markers and using the option "hap-logistic". Linkage disequilibrium $(\mathrm{LD})$ was also analyzed using PLINK.

\section{Results}

CEACAM6 variants are not associated with IBD susceptibility

The genotyping success rates were at least 99\% for all eight SNPs tested and were comparable between the controls and the $\mathrm{CD}$ and $\mathrm{UC}$ patients groups. In all three subgroups $(\mathrm{CD}, \mathrm{UC}$, and controls), the allele frequencies of the CEACAM6 SNPs rs10415946, rs1805223 = p.Pro42Pro, rs4803507, rs4803508, rs11548735 = p.Gly239Val, $\quad$ rs7246116 $=$ p.His260His,$\quad$ rs2701, rs10416839 were in accordance with the predicted HardyWeinberg equilibrium (Table 4). Overall, we observed no significant differences in the frequencies of the investigated CEACAM6 SNPs in GD and UG patients compared to healthy controls (Table 4) implicating no significant association of CEACAM6 variants and IBD susceptibility. Only two patients (both with UC) were minor allele carriers of the rare CEACAM6 SNP rs7246116 $=$ p.His260His, therefore not allowing a comparative analysis of this SNP regarding CD susceptibility.

\section{CEACAM6 haplotypes are not associated with CD and UC} susceptibility

Considering recent evidence showing that certain CEACAM6 haplotypes modulate susceptibility to bacterial infections [38], we next performed a detailed haplotype analysis in our IBD cohort. However, as shown in Tables 5 and 6, we could not demonstrated significant associations of CEACAM6 haplotypes with $\mathrm{CD}$ and $\mathrm{UC}$ susceptibility.

The CEACAM6 variants are not associated with an ileal disease phenotype in $C D$ patients

Since GEACAM6 has recently shown to act as a receptor for AIEC, thereby promoting bacterial colonization in ileal CD [19], we further investigated whether CEACAM6 SNPs are associated with ileal disease in $\mathrm{CD}$ patients. Based on a phenotype analysis according to the Montreal classification of IBD [33], the detailed phenotypic data available from a subcohort of $667 \mathrm{CD}$ patients was analyzed for disease localization. None of the investigated CEACAM6 SNPs was associated with ileal or ileocolonic CD

Table 9. Analysis for gene-gene interaction with CEACAM6.and IL23R variants regarding susceptibility to Crohn's disease (CD).

\begin{tabular}{|c|c|c|c|c|c|c|c|c|}
\hline $\begin{array}{l}\text { CEACAM6 } \\
\text { SNPS } \\
\text { IL23R SNPs }\end{array}$ & rs 10415946 & rs1805223 & rs4803507 & rs4803508 & rs11548735 & rs7246116 & rs2701 & rs10416839 \\
\hline rs1004819 & 0.13 & 0.31 & 0.29 & 0.50 & 0.46 & $*$ & 0.52 & 0.95 \\
\hline rs7517847 & 0.67 & 0.20 & 0.31 & 0.17 & 0.23 & * & 0.27 & 0.81 \\
\hline rs10489629 & 0.64 & 0.09 & 0.11 & 0.97 & 0.79 & * & 0.71 & 0.98 \\
\hline rs2201841 & 0.52 & 0.42 & 0.40 & 0.61 & 0.50 & * & 0.46 & 0.63 \\
\hline rs11465804 & 0.20 & 0.13 & 0.19 & 0.59 & 0.26 & $*$ & 0.32 & 0.76 \\
\hline rs11209026 & 0.08 & 0.05 & 0.08 & 0.35 & 0.28 & $*$ & 0.35 & 0.91 \\
\hline rs1343151 & 0.35 & 0.04 & 0.06 & 0.83 & 0.57 & * & 0.60 & 0.64 \\
\hline rs10889677 & 0.55 & 0.48 & 0.44 & 0.77 & 0.66 & * & 0.62 & 0.51 \\
\hline rs11209032 & 0.43 & 0.52 & 0.53 & 0.87 & 0.99 & * & 0.89 & 0.19 \\
\hline rs1495965 & 0.47 & 0.66 & 0.58 & 0.73 & 0.61 & $*$ & 0.84 & 0.32 \\
\hline
\end{tabular}

p-values for epistasis between CEACAM6.and IL23R SNPs in the CD case-control sample. After Bonferroni correction, the association highlighted in bold did not remain significant.

*There were no carriers of the minor allele of rs7146116 in the CD and control cohort.

doi:10.1371/journal.pone.0019319.t009 
Table 10. Analysis for gene-gene interaction between CEACAM6 and ATGT16L1 variants regarding susceptibility to Crohn's disease (CD).

\begin{tabular}{|c|c|c|c|c|c|c|c|c|}
\hline $\begin{array}{l}\text { CEACAM6 } \\
\text { SNPs } \\
\text { ATG16L1 SNPs }\end{array}$ & rs10415946 & rs1805223 & rs4803507 & rs4803508 & rs11548735 & rs7246116 & rs2701 & rs10416839 \\
\hline rs13412102 & 0.89 & 0.89 & 0.72 & 0.89 & 0.55 & $*$ & 0.55 & 0.79 \\
\hline rs12471449 & 0.49 & 0.44 & 0.40 & 0.74 & 0.58 & $*$ & 0.56 & 0.04 \\
\hline rs6431660 & 0.53 & 0.66 & 0.50 & 0.87 & 0.98 & * & 0.93 & 0.66 \\
\hline rs1441090 & 0.56 & 0.32 & 0.26 & 0.78 & 0.89 & $*$ & 0.95 & 0.27 \\
\hline rs2289472 & 0.67 & 0.65 & 0.49 & 0.67 & 0.86 & $*$ & 0.83 & 0.57 \\
\hline rs2241880 & 0.84 & 0.74 & 0.57 & 0.64 & 0.81 & * & 0.83 & 0.58 \\
\hline rs2241879 & 0.93 & 0.81 & 0.68 & 0.74 & 0.73 & $*$ & 0.72 & 0.56 \\
\hline rs3792106 & 0.67 & 0.52 & 0.44 & 0.50 & 0.69 & $*$ & 0.73 & 0.83 \\
\hline rs4663396 & 0.81 & 0.93 & 0.80 & 0.56 & 0.85 & $*$ & 0.90 & 0.15 \\
\hline
\end{tabular}

p-values for epistasis between CEACAM6 and ATGT16L1 SNPs in the CD case-control sample. After Bonferroni correction, the association highlighted in bold did not remain significant.

*There were no carriers of the minor allele of rs7146116 in the CD and control cohort.

doi:10.1371/journal.pone.0019319.t010

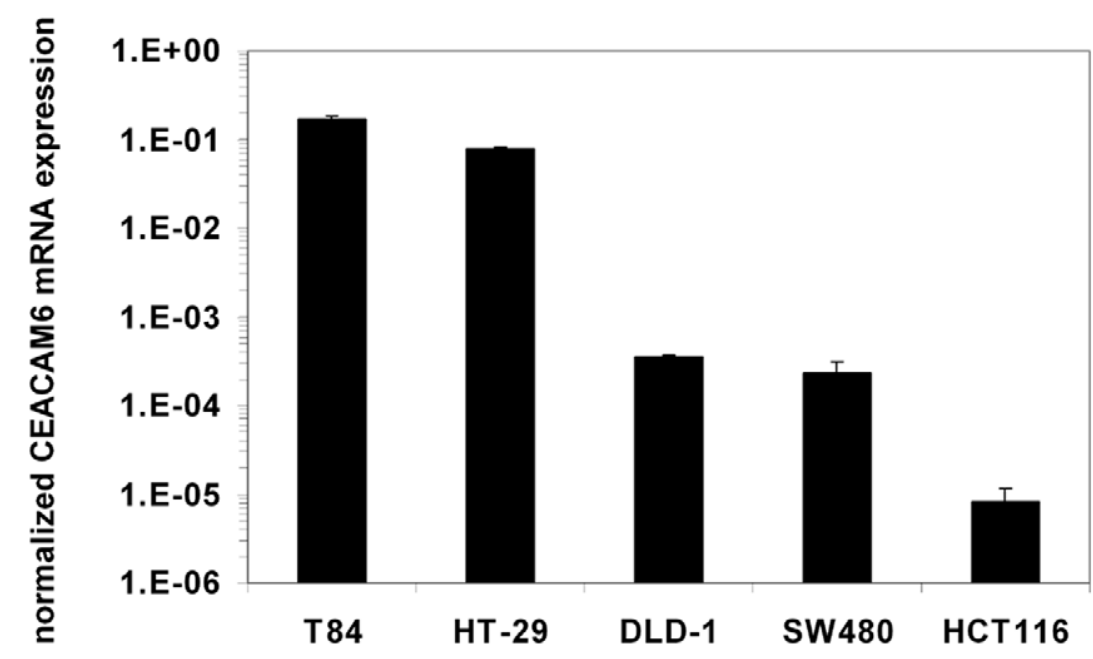

cell line

\begin{tabular}{|c|c|c|c|c|c|}
\hline SNP ${ }^{\text {cell line }}$ & T84 & HT-29 & DLD-1 & SW480 & НСТ116 \\
\hline rs10415946 & $A G$ & $A A$ & AA & AA & AA \\
\hline rs1805223 & GG & AG & AG & AG & $A G$ \\
\hline rs4803507 & GG & GG & GG & GG & GG \\
\hline rs4803508 & $A A$ & GG & $A A$ & $A A$ & GG \\
\hline rs11548735 & GT & GT & $\mathrm{TT}$ & TT & GG \\
\hline rs7246116 & GG & GG & GG & GG & GG \\
\hline rs2701 & $A G$ & $A G$ & GG & GG & $A \boldsymbol{A}$ \\
\hline rs10416839 & GT & GT & GG & GG & $T T$ \\
\hline
\end{tabular}

Figure 2. Analysis of CEACAM6 gene expression and CEACAM6 gene variants in intestinal epithelial cell (IEC) lines. (A) Total RNA isolated from IEC lines as indicated was reverse transcribed and was analyzed for CEACAM6 gene expression by quantitative PCR. T84 cells express CEACAM6 at the highest level followed by HT-29 cells, and intermediate CEACAM6 expression was found in SW480 and DLD-1 cells. CEACAM6 expression was close to the detection limit after 40 PCR cycles in HCT116 cells (note the logarithmic scale on the $y$-axis). CEACAM6 expression was normalized to $\beta$-actin expression in the respective CDNA samples. (B) Genomic DNA was isolated from IEC lines and 8 SNPs in CEACAM6 were analyzed as indicated by DNA sequencing. The respective alleles for these SNPs in each cell line are depicted in the table. This analysis revealed that T84, the cell line with the highest CEACAM6 expression, and HCT116 cells, the cell line with the lowest CEACAM6 expression, are the only IEC lines with unique genotypes for certain CEACAM6 SNPs (depicted in bold italic). DLD-1 and SW480 cells have identical genotypes for all SNPs analyzed and nearly identical CEACAM6 expression levels. doi:10.1371/journal.pone.0019319.g002 
(Table 7). However, we have to acknowledge that the sample size has limited power to detect weak disease associations. For example, based on 667 patients with a L1/L3 disease phenotype, a minor allele frequency of 0.40 and an OR of 1.1 , the power is $28.88 \%$ to detect an effect on a significance level of 5\% (Genetic Power Calculator, http://pngu.mgh.harvard.edu/ purcell/gpc/).

\section{Analysis for gene-gene interaction with $C D$-associated NOD2, IL23R and ATG16L1 variants}

Given the raising evidence for a key role of CEACAM6 in the complex interaction of the mucosal immune system and intestinal bacteria, we next analyzed for potential epistasis between CEACAM6 SNPs (rs10415946, rs 1805223 = p.Pro42Pro, rs4803507, rs4803508, rs11548735 = p.Gly239Val, rs7246116 = pHis260His, rs2701, rs10416839 ) and the three main CD-associated NOD2/CARD15 variants p.Arg702Trp (rs2066844), p.Gly908Arg (rs2066845), and p.Leu1007fsX1008 (rs2066847) which have previously shown to be strongly associated with CD and ileal disease localization. However, there was no evidence for epistasis between the CEACAM6 SNPs and the three analyzed $N O D 2 / C A R D 15$ variants (Table 8 ).

Recently, we demonstrated an association of the IL23R SNP rs1004819 (TT homozygous carriers) with ileal CD [34]. Therefore, we also analyzed for potential gene-gene interaction between CEACAM6 SNPs and the major CD-associated IL23R variants. However, we did not find evidence for epistasis between CEACAM6 and IL23R regarding CD susceptibility (Table 9).

In addition, novel findings indicate a major role for ATG16L1 in Paneth cell development in the terminal ileum. Therefore, we also analyzed for potential epistasis between the CEACAM6 SNPs and the major CD-associated ATG16L1 SNPs. However, we were also unable to demonstrate evidence for epistasis between these two genes (Table 10).

p-values for epistasis between CEACAM6 and ATGT16L1 SNPs in the CD case-control sample. After Bonferroni correction, the association highlighted in bold did not remain significant.

*There were no carriers of the minor allele of rs7146116 in the CD and control cohort.

\section{CEACAM6 genotypes modulate CEACAM6 expression in intestinal epithelial cell lines}

To analyze a potential influence of CEACAM6 gene variants on CEACAM6 gene expression, we determined CEACAM6 mRNA levels in five intestinal epithelial cell (IEC) lines DLD-1, HCT116, HT-29, SW480 and T84 by quantitative PCR. This analysis revealed considerable differences in CEACAM6 expression depending on the cell line. While T84 cells showed the highest expression, the expression in HCT116 cells was four orders of magnitude smaller and close to the detection limit (Fig. 2A).

Table 11. Analysis for linkage disequilibrium between CEACAM6 SNPs in patients with Crohn's disease.

\begin{tabular}{llllll}
\hline \multicolumn{7}{c}{ rs10415946 } & rs4803507 & rs4803508 & rs2701 & rs10416839 \\
\hline rs10415946 & $*$ & $*$ & $*$ & $*$ & $*$ \\
rs4803507 & $0.65 / 0.96$ & $*$ & $*$ & $*$ & $*$ \\
rs4803508 & $0.12 / 0.58$ & $0.09 / 0.59$ & $*$ & $*$ & $*$ \\
rs2701 & $0.12 / 0.53$ & $0.10 / 0.57$ & $0.80 / 0.95$ & $*$ & $*$ \\
rs10416839 & $<0.01 / 0.03$ & $<0.01 / 0.13$ & $0.25 / 0.85$ & $0.31 / 0.90$ & $*$ \\
\hline
\end{tabular}

Values are given as $\mathrm{r}^{2} / \mathrm{D}^{\prime}$-measurements.

doi:10.1371/journal.pone.0019319.t011
Table 12. Analysis for linkage disequilibrium between CEACAM6 SNPs in patients with ulcerative colitis.

\begin{tabular}{llllll}
\hline \multicolumn{7}{c}{ rs10415946 } & rs4803507 & rs4803508 & rs2701 & rs10416839 \\
\hline rs10415946 & $*$ & $*$ & $*$ & $*$ & $*$ \\
rs4803507 & $0.70 / 0.98$ & $*$ & $*$ & $*$ & $*$ \\
rs4803508 & $0.15 / 0.65$ & $0.11 / 0.67$ & $*$ & $*$ & $*$ \\
rs2701 & $0.14 / 0.61$ & $0.10 / 0.60$ & $0.87 / 0.97$ & $*$ & $*$ \\
rs10416839 & $<0.01 / 0.09$ & $<0.01 / 0.11$ & $0.29 / 0.89$ & $0.33 / 0.91 *$ \\
\hline
\end{tabular}

Values are given as $\mathrm{r}^{2} / \mathrm{D}^{\prime}$-measurements.

doi:10.1371/journal.pone.0019319.t012

SW480 and DLD-1 cells showed similar, intermediate expression (Fig. 2A). Interestingly, when these cell lines were analyzed for CEACAM6 gene variants, only T84 and HCT 116 cells, the two cell lines with the highest and lowest CEACAM6 expression, respectively, had unique genotype variants when compared with the other cell lines (Fig. 2B). While T84 cells were the only cells that had a unique genotype for rs10415946 and rs $1805223=$ p.Pro42Pro, HCT116 had a unique genotype in SNPs rs11548735 = p.Gly239Val, rs2701 and rs10416839. SW480 and DLD-1 cells had identical CEACAM6 genotypes and their CEACAM6 expression was nearly identical (Fig. 2A and 2B). A detailed analysis regarding linkage disequilibrium between the investigated CEACAM6 SNPs stratified for $\mathrm{CD}, \mathrm{UC}$ and controls is given in Tables 11, 12 and 13.

\section{Discussion}

In summary, our study represents the first detailed analysis of CEACAM6 SNPs regarding disease susceptibility and phenotypic consequences in IBD patients. Compared to previous GWAS, our study had a more complete coverage of the CEACAM6 gene region (see details in Table 14). Overall, we did not observe a significant influence of the investigated CEACAM6 SNPs on CD and UC susceptibility. Moreover, a detailed haplotype analysis did not reveal significant associations with IBD susceptibility. CEACAM6 has recently shown to act as a receptor for AIEC suggesting an important role in bacterial colonization of the ileal mucosa in CD patients [19]. However, none of the investigated CEACAM6 SNPs was associated with ileal or ileocolonic CD.

Interestingly, a recent study demonstrated that the defect in CEACAM family members in intestinal epithelial cells isolated from CD patients appears to be related to the aberrant nuclear localization of the transcription factor SOX9 [39] which regulates cell proliferation and is required for Paneth cell differentiation in

Table 13. Analysis for linkage disequilibrium between CEACAM6 SNPs in controls.

\begin{tabular}{llllll}
\hline \multicolumn{7}{c}{ rs10415946 rs4803507 } & rs4803508 rs2701 & rs10416839 \\
\hline rs10415946 & $*$ & $*$ & $*$ & $*$ & $*$ \\
rs4803507 & $0.68 / 0.98$ & $*$ & $*$ & $*$ & $*$ \\
rs4803508 & $0.15 / 0.63$ & $0.09 / 0.60$ & $*$ & $*$ & $*$ \\
rs2701 & $0.14 / 0.60$ & $0.09 / 0.57$ & $0.81 / 0.94$ & $*$ & $*$ \\
rs10416839 & $0.01 / 0.12$ & $<0.01 / 0.06$ & $0.23 / 0.84$ & $0.29 / 0.90 *$ \\
\hline
\end{tabular}

Values are given as $r^{2} / D^{\prime}$-measurements.

doi:10.1371/journal.pone.0019319.t013 
Table 14. Coverage of the CEACAM6 gene region by the Illumina Hap300 chip and the Affymetrix 500 k chip utilized in previous genome-wide association studies (GWAS).

\begin{tabular}{|c|c|c|c|c|}
\hline $\begin{array}{l}\text { Chromosomal position } \\
\text { (bp) of the CEACAM6 SNP }\end{array}$ & $\begin{array}{l}\text { Position in the } \\
C E A C A M 6^{*} \text { gene }\end{array}$ & $\begin{array}{l}\text { CEACAM6 SNPs analyzed } \\
\text { in our study }\end{array}$ & $\begin{array}{l}\text { CEACAM6 SNPs covered by } \\
\text { the Illumina Hap } 300 \text { chip }\end{array}$ & $\begin{array}{l}\text { CEACAM6 SNPs covered } \\
\text { by the Affymetrix } 500 k \\
\text { chip }\end{array}$ \\
\hline $46,948,446$ & upstream & & rs3764577 & \\
\hline $46,950,899$ & upstream & rs10415946 & & \\
\hline $46,952,409$ & intragenic & rs1805223 = P42P & & \\
\hline $46,953,560$ & intragenic & & & rs3795018 \\
\hline $46,954,095$ & intragenic & & & rs11669653 \\
\hline $46,954,731$ & intragenic & & rs3795020 & \\
\hline $46,955,390$ & intragenic & rs4803507 & & \\
\hline $46,956,489$ & intragenic & rs4803508 & & \\
\hline $46,957,729$ & intragenic & rs11548735= G239V & & \\
\hline $46,957,793$ & intragenic & $\mathrm{rs} 7246116=\mathrm{H} 260 \mathrm{H}$ & & \\
\hline $46,962,846$ & intragenic & & rs10413359 & \\
\hline $46,966,939$ & intragenic & rs2701 & & rs2701 \\
\hline $46,970,128$ & downstream & & & rs6508997 \\
\hline $46,972,172$ & downstream & rs10416839 & rs10416839 & \\
\hline
\end{tabular}

*Position of the CEACAM6 gene on chromosome 19: $46,951,341$ bp to $46,967,953 \mathrm{bp}$.

doi:10.1371/journal.pone.0019319.t014

the intestinal epithelium $[40,41]$. However, ileal CD is characterized by a specific decrease in Paneth cell alpha-defensins and defective Paneth cell-mediated host defense [42] which has been linked to the NOD2 genotype [43], although this finding is opposed by the results of a recent study [44], and additional modifiers of Paneth cell function such as XBP1 are involved [45]. Therefore, one might speculate whether the role of CEACAM6 in ileal bacterial colonization is regulated via SOX9 expression implicating defective Paneth cell function in patients with small bowel CD. Given the association of defensin secretion with the NOD2 genotype [43] and the findings of numerous previous studies including studies from our IBD center demonstrating ileal disease localization in CD patients with NOD2 mutations [37,46,47], we also tested for potential gene-gene interaction of CEACAM 6 and NOD2. However, we found no evidence for epistasis between these two genes regarding CD susceptibility. Further functional studies analyzing the complex interaction of intestinal CEACAM6 expression and bacterial adherence in the gut particularly of CD patients carrying CEACAM6 variants will therefore be required. Given the important role of ATG16L1 in Paneth cell development of the terminal ileum and the role of $I L 23 R$ in the development of proinflammatory Th17 cells, we also analyzed for epistasis of these two genes with CEACAM6 but were unable to find evidence for significant epistasis of these genes regarding CD susceptibility.

Interestingly, a recent study indicated that CEACAM6 and a regulatory element near the $3^{\prime}$ end of CEACAM3 are associated with disease severity in patients with cystic fibrosis [48]. However, a previous study in IBD patients suggested that heterozygous carriers of the $\triangle F 508$ mutation in the CFTR gene, the main susceptibility gene for patients with cystic fibrosis, might exert a protective effect in CD [49], suggesting opposing effects of genetic risk loci for cystic fibrosis and IBD.

In the meta-analysis of Barrett et al. [50], a SNP (rs4807569) within the chromosomal region $19 \mathrm{q} 13$, in which the CEACAM6 gene is located, was weakly associated with $\mathrm{CD}$, but this association could not be confirmed in a replication cohort. In the recent meta-analysis of Franke et al. [51], two SNPs (rs
736289 and rs281376) within this region were strongly associated with CD. However, the distance between these SNPs and the CEACAM6 gene is 9 and 7 megabases, respectively, and thus, the disease causing variant within this region remains to be identified.

CEACAM6 is also a major target gene for Smad3-mediated TGF- $\beta$ signaling [52]. Since Smad3 differentially regulates the induction of regulatory and inflammatory Th17 cell differentiation [53], which are key players in the IBD pathogenesis [54], further investigations analyzing Th17 cell differentiation in IBD patients carrying CEACAM6 variants might also be of high interest. Moreover, very recent evidence from studies in mice demonstrated that colonization of the small intestine with a single commensal microbe, segmented filamentous bacterium (SFB), is sufficient to induce Th17 cells in the lamina propria [55]. These SFB adhere tightly to the surface of epithelial cells in the terminal ileum of mice with Th17 cells but are absent from mice that have few Th17 cells [55]. Further studies will have to characterize if SFB adherence is mediated (similar to AIEC adherence) by CEACAM family members.

In summary, we performed the first systemic analysis of CEACAM6 gene variants in IBD patients. Despite the great importance of CEACAM6 as receptor for AIEC on the ileal mucosa of CD patients, we were unable to demonstrate a specific role of CEACAM6 variants in IBD susceptibility. Furthermore, there was no evidence for an association with ileal $\mathrm{CD}$ or for epistasis with NOD2, IL23R, and ATG16L1 variants in CD susceptibility. Further functional studies will be necessary to elucidate how CEACAM6 gene variants may modulate bacterial colonization in IBD patients. Even if this study was unable to find a role for CEACAM6 gene variants in IBD susceptibility, the CEACAM6 protein is likely to be an important mediator of the pathogenesis of CD [56].

\section{Acknowledgments}

This work contains parts of the unpublished degree theses of C. Fries. 


\section{Author Contributions}

Conceived and designed the experiments: JG JD SB. Performed the experiments: JG CF JD. Analyzed the data: JG SP CW BM-M JD DC SB. Contributed reagents/materials/analysis tools: JG JS CF CT SP MW FB

\section{References}

1. Xavier RJ, Podolsky DK (2007) Unravelling the pathogenesis of inflammatory bowel disease. Nature 448: 427-434.

2. Podolsky DK (2002) Inflammatory bowel disease. N Engl J Med 347: 417-429.

3. Mudter J, Neurath MF (2007) Apoptosis of $\mathrm{T}$ cells and the control of inflammatory bowel disease: therapeutic implications. Gut 56: 293-303.

4. Parkes M, Barrett JC, Prescott NJ, Tremelling M, Anderson CA, et al. (2007) Sequence variants in the autophagy gene IRGM and multiple other replicating loci contribute to Crohn's disease susceptibility. Nat Genet 39: 830-832.

5. Hampe J, Franke A, Rosenstiel P, Till A, Teuber M, et al. (2007) A genome-wide association scan of nonsynonymous SNPs identifies a susceptibility variant for Crohn disease in ATG16L1. Nat Genet 39: 207-211.

6. Cooney R, Baker J, Brain O, Danis B, Pichulik T, et al. (2010) NOD2 stimulation induces autophagy in dendritic cells influencing bacterial handling and antigen presentation. Nat Med 16: 90-97.

7. Travassos LH, Carneiro LA, Ramjeet M, Hussey S, Kim YG, et al. (2010) Nod1 and Nod2 direct autophagy by recruiting ATG16L1 to the plasma membrane at the site of bacterial entry. Nat Immunol 11: 55-62.

8. Sydora BC, Macfarlane SM, Walker JW, Dmytrash AL, Churchill TA, et al. (2007) Epithelial barrier disruption allows nondisease-causing bacteria to initiate and sustain IBD in the IL-10 gene-deficient mouse. Inflamm Bowel Dis 13: 947-954.

9. Silva MA (2009) Intestinal dendritic cells and epithelial barrier dysfunction in Crohn's disease. Inflamm Bowel Dis 15: 436-453.

10. Hugot JP, Chamaillard M, Zouali H, Lesage S, Cezard JP, et al. (2001) Association of NOD2 leucine-rich repeat variants with susceptibility to Crohn's disease. Nature 411: 599-603.

11. Ogura Y, Bonen DK, Inohara N, Nicolae DL, Chen FF, et al. (2001) A frameshift mutation in NOD2 associated with susceptibility to Crohn's disease. Nature 411: 603-606.

12. Duerr RH, Taylor KD, Brant SR, Rioux JD, Silverberg MS, et al. (2006) A genome-wide association study identifies IL23R as an inflammatory bowel disease gene. Science 314: 1461-1463.

13. Pineton de Chambrun G, Colombel JF, Poulain D, Darfeuille-Michaud A (2008) Pathogenic agents in inflammatory bowel diseases. Curr Opin Gastroenterol 24: $440-447$.

14. Sokol H, Lay C, Seksik P, Tannock GW (2008) Analysis of bacterial bowel communities of IBD patients: what has it revealed? Inflamm Bowel Dis 14: 858-867.

15. Cario E, Podolsky DK (2006) Toll-like receptor signaling and its relevance to intestinal inflammation. Ann N Y Acad Sci 1072: 332-338.

16. Rhodes JM (2007) The role of Escherichia coli in inflammatory bowel disease. Gut 56: 610-612.

17. Rolhion N, Darfeuille-Michaud A (2007) Adherent-invasive Escherichia coli in inflammatory bowel disease. Inflamm Bowel Dis 13: 1277-1283.

18. Carvalho FA, Barnich N, Sivignon A, Darcha C, Chan CH, et al. (2009) Crohn's disease adherent-invasive Escherichia coli colonize and induce strong gut inflammation in transgenic mice expressing human CEACAM. J Exp Med 206: 2179-2189.

19. Barnich N, Carvalho FA, Glasser AL, Darcha C, Jantscheff P, et al. (2007) CEACAM6 acts as a receptor for adherent-invasive E. coli, supporting ileal mucosa colonization in Crohn disease. J Clin Invest 117: 1566-1574.

20. Khan WN, Frangsmyr L, Teglund S, Israelsson A, Bremer K, et al. (1992) Identification of three new genes and estimation of the size of the carcinoembryonic antigen family. Genomics 14: 384-390.

21. Obrink B (1997) CEA adhesion molecules: multifunctional proteins with signalregulatory properties. Curr Opin Cell Biol 9: 616-626.

22. Kuespert K, Pils S, Hauck CR (2006) CEACAMs: their role in physiology and pathophysiology. Curr Opin Cell Biol 18: 565-571.

23. Thom I, Schult-Kronefeld O, Burkholder I, Schuch G, Andritzky B, et al. (2009) Expression of CEACAM-1 in pulmonary adenocarcinomas and their metastases. Anticancer Res 29: 249-254.

24. Greicius G, Severinson E, Beauchemin N, Obrink B, Singer BB (2003) CEACAM1 is a potent regulator of $\mathrm{B}$ cell receptor complex-induced activation. J Leukoc Biol 74: 126-134

25. Muenzner P, Rohde M, Kneitz S, Hauck CR (2005) CEACAM engagement by human pathogens enhances cell adhesion and counteracts bacteria-induced detachment of epithelial cells. J Cell Biol 170: 825-836.

26. Nagaishi T, Iijima H, Nakajima A, Chen D, Blumberg RS (2006) Role of CEACAM1 as a regulator of T cells. Ann N Y Acad Sci 1072: 155-175.

27. Dango S, Sienel W, Schreiber M, Stremmel C, Kirschbaum A, et al. (2008) Elevated expression of carcinoembryonic antigen-related cell adhesion molecule 1 (CEACAM-1) is associated with increased angiogenic potential in non-smallcell lung cancer. Lung Cancer 60: 426-433.
TOlszak UL BG TOchsenkühn CW PL BM-M JD DG SB. Wrote the paper: JS JG DC JD SB. Organized the collaboration between the research institutions: SB.

28. Nagaishi T, Pao L, Lin SH, Iijima H, Kaser A, et al. (2006) SHP1 phosphatasedependent $\mathrm{T}$ cell inhibition by CEACAM1 adhesion molecule isoforms. Immunity 25: 769-781.

29. Gray-Owen SD, Blumberg RS (2006) CEACAM1: contact-dependent control of immunity. Nat Rev Immunol 6: 433-446.

30. Boudeau J, Glasser AL, Masseret E, Joly B, Darfeuille-Michaud A (1999) Invasive ability of an Escherichia coli strain isolated from the ileal mucosa of a patient with Crohn's disease. Infect Immun 67: 4499-4509.

31. Glasser AL, Boudeau J, Barnich N, Perruchot MH, Colombel JF, et al. (2001) Adherent invasive Escherichia coli strains from patients with Crohn's disease survive and replicate within macrophages without inducing host cell death. Infect Immun 69: 5529-5537.

32. Lennard-Jones JE (1989) Classification of inflammatory bowel disease. Scand J Gastroenterol Suppl 170: 2-6; discussion 16-19.

33. Silverberg MS, Satsangi J, Ahmad T, Arnott ID, Bernstein GN, et al. (2005) Toward an integrated clinical, molecular and serological classification of inflammatory bowel disease: Report of a Working Party of the 2005 Montreal World Congress of Gastroenterology. Can J Gastroenterol 19 Suppl A: 5-36.

34. Glas J, Seiderer J, Wetzke M, Konrad A, Torok HP, et al. (2007) rs1004819 is the main disease-associated IL23R variant in German Crohn's disease patients: combined analysis of IL23R, CARD15, and OCTN1/2 variants. PLoS ONE 2: e819.

35. Glas J, Stallhofer J, Ripke S, Wetzke M, Pfennig S, et al. (2009) Novel genetic risk markers for ulcerative colitis in the IL2/IL21 region are in epistasis with IL23R and suggest a common genetic background for ulcerative colitis and celiac disease. Am J Gastroenterol 104: 1737-1744.

36. Glas J, Seiderer J, Pasciuto G, Tillack C, Diegelmann J, et al. (2009) rs224136 on chromosome 10q21.1 and variants in PHOX2B, NCF4, and FAM92B are not major genetic risk factors for susceptibility to Crohn's disease in the German population. Am J Gastroenterol 104: 665-672.

37. Seiderer J, Schnitzler F, Brand S, Staudinger T, Pfennig S, et al. (2006) Homozygosity for the CARD 15 frameshift mutation $1007 \mathrm{fs}$ is predictive of early onset of Crohn's disease with ileal stenosis, entero-enteral fistulas, and frequent need for surgical intervention with high risk of re-stenosis. Scand J Gastroenterol 41: 1421-1432.

38. Callaghan MJ, Rockett K, Banner C, Haralambous E, Betts H, et al. (2008) Haplotypic diversity in human CEACAM genes: effects on susceptibility to meningococcal disease. Genes Immun 9: 30-37.

39. Roda G, Dahan S, Mezzanotte L, Caponi A, Roth-Walter F, et al. (2009) Defect in CEACAM family member expression in Crohn's disease IECs is regulated by the transcription factor SOX9. Inflamm Bowel Dis 15: 1775-1783.

40. Bastide P, Darido C, Pannequin J, Kist R, Robine S, et al. (2007) Sox9 regulates cell proliferation and is required for Paneth cell differentiation in the intestinal epithelium. J Cell Biol 178: 635-648.

41. Mori-Akiyama Y, van den Born M, van Es JH, Hamilton SR, Adams HP, et al. (2007) SOX9 is required for the differentiation of paneth cells in the intestinal epithelium. Gastroenterology 133: 539-546.

42. Wehkamp J, Salzman NH, Porter E, Nuding S, Weichenthal M, et al. (2005) Reduced Paneth cell alpha-defensins in ileal Crohn's disease. Proc Natl Acad Sci U S A 102: 18129-18134.

43. Wehkamp J, Harder J, Weichenthal M, Schwab M, Schaffeler E, et al. (2004) NOD2 (CARD15) mutations in Crohn's disease are associated with diminished mucosal alpha-defensin expression. Gut 53: 1658-1664.

44. Simms LA, Doecke JD, Walsh MD, Huang N, Fowler EV, et al. (2008) Reduced alpha-defensin expression is associated with inflammation and not NOD2 mutation status in ileal Crohn's disease. Gut 57: 903-910.

45. Kaser A, Lee AH, Franke A, Glickman JN, Zeissig S, et al. (2008) XBP1 links ER stress to intestinal inflammation and confers genetic risk for human inflammatory bowel disease. Cell 134: 743-756.

46. Seiderer J, Brand S, Herrmann KA, Schnitzler F, Hatz R, et al. (2006) Predictive value of the CARD 15 variant $1007 \mathrm{fs}$ for the diagnosis of intestinal stenoses and the need for surgery in Crohn's disease in clinical practice: results of a prospective study. Inflamm Bowel Dis 12: 1114-1121.

47. Schnitzler F, Brand S, Staudinger T, Pfennig S, Hofbauer K, et al. (2006) Eight novel CARD15 variants detected by DNA sequence analysis of the CARD15 gene in 111 patients with inflammatory bowel disease. Immunogenetics 58: 99-106.

48. Stanke F, Becker T, Hedtfeld S, Tamm S, Wienker TF, et al. (2010) Hierarchical fine mapping of the cystic fibrosis modifier locus on $19 \mathrm{q} 13$ identifies an association with two elements near the genes CEACAM3 and CEACAM6. Hum Genet 127: 383-394.

49. Bresso F, Askling J, Astegiano M, Demarchi B, Sapone N, et al. (2007) Potential role for the common cystic fibrosis DeltaF508 mutation in Crohn's disease. Inflamm Bowel Dis 13: 531-536. 
50. Barrett JC, Hansoul S, Nicolae DL, Cho JH, Duerr RH, et al. (2008) Genomewide association defines more than 30 distinct susceptibility loci for Crohn's disease. Nat Genet 40: 955-962.

51. Franke A, McGovern DPB, Barrett JC, Wang K, Radford-Smith GL, et al. (2010) Genome-wide meta-analysis increases to 71 the number of confirmed Crohn's disease susceptibility loci. Nat Genet 42: 1118-1121.

52. Han SU, Kwak TH, Her KH, Cho YH, Choi C, et al. (2008) CEACAM5 and CEACAM6 are major target genes for Smad3-mediated TGF-beta signaling. Oncogene 27: 675-683.
53. Martinez GJ, Zhang Z, Chung Y, Reynolds JM, Lin X, et al. (2009) Smad3 differentially regulates the induction of regulatory and inflammatory $\mathrm{T}$ cell differentiation. J Biol Chem 284: 35283-35286.

54. Brand S (2009) Crohn's disease: Th1, Th17 or both? The change of a paradigm: new immunological and genetic insights implicate Th17 cells in the pathogenesis of Crohn's disease. Gut 58: 1152-1167.

55. Ivanov II, Atarashi K, Manel N, Brodie EL, Shima T, et al. (2009) Induction of intestinal Th17 cells by segmented filamentous bacteria. Cell 139: 485-498.

56. Abraham C, Cho JH (2007) Bugging of the intestinal mucosa. N Engl J Med 357: $708-710$ 